\title{
Evaluation of Cold Workplaces: An Overview of Standards for Assessment of Cold Stress
}

\author{
Ingvar HOLMÉR ${ }^{1}$
}

\begin{abstract}
${ }^{1}$ Thermal Environment Laboratory, Department of Design Sciences, Faculty of Engineering, Lund University, 22100 Lund, Sweden
\end{abstract}

Received September 4, 2008 and accepted December 16, 2008

\begin{abstract}
Many persons world wide are exposed to cold environments, either indoors for example in cold stores, or outdoors. Cold is a hazard to health and may affect safety and performance of work. Basis for the creation of safe and optimal working conditions may be obtained by the application of relevant international standards. ISO $11079^{1)}$ presents a method for evaluation of whole body heat balance. On the basis of climate and activity a required clothing insulation (IREQ) for heat balance is determined. For clothing with known insulation value an exposure time limited is calculated. ISO 11079 also includes criteria for assessment of local cooling. Finger temperatures should not be below $24^{\circ} \mathrm{C}$ during prolonged exposures or $15^{\circ} \mathrm{C}$ occasionally. Wind chill temperature indicates the risk of bare skin to freeze for combinations of wind and low temperatures. Special protection of airways is recommended at temperatures below $-20^{\circ} \mathrm{C}$, in particular during heavy work. Additional standards are available describing evaluation strategies, work place observation checklists and checklist for medical screening. Risks associated with contact with cold surfaces can be evaluated with ISO $13732^{2}$. The strategy and principles for assessment and prevention of cold stress are reviewed in this paper.
\end{abstract}

Key words: Body temperature, Method, Skin temperature, Standards, Cooling

\section{Introduction}

Exposure to cold is a major hazard in outdoor work in many parts of the world, in particular during the winter season $^{3)}$. It is also present in many types of indoor work, for example in the food processing industry. Cold endangers the body's heat balance and requires behavioural action to control heat losses. Clothing is the natural and most common measure for this purpose. However, clothing for cold protection may be bulky and heavy, affecting performance and increasing muscular strain and work load. Also other environmental factors such as snow, ice and darkness increase the stress level and the risk for accidents. More severe effects of cold are caused by tissue cooling. Superficial tissue cooling causes discomfort, which may affect arousal, vigilance and concentration ${ }^{4)}$. More profound cooling of for example extremities impairs their function ${ }^{5)}$. Neuro-muscular function of hands and fingers is impaired and affects dexterity. Cold feet affect balance $^{6}$ and walking and may increase the risk of slipping7). Cooling to low skin temperatures causes pain, numbness and eventually local frostbite ${ }^{8,9)}$. Whole body cooling results in a sequel of effects with pronounced effect on mental and physical performance and function, eventually ending up in a risk of death from hypothermia during long exposures ${ }^{9-11)}$. International standards are readily available for assessment of various types of cold stress and can be incorporated in a risk management program $^{12)}$. This paper reviews available methods and is an updated and extended version of a previous review ${ }^{10}$ ).

\section{Strategy for assessment of cold stress}

A systematic approach to the evaluation and solution of cold related problems in the workplace comprises an action program in several steps ${ }^{13)}$. The principle idea behind this strategy is an attempt to solve the observed problems with as simple methods as possible. Only when problems become complex and require costly preventive measures, comprehensive investigations and measurements are carried out by qualified experts. Table 1 summarizes the main components of the program. 
Table 1. Components of a strategy for stepwise assessment of cold problems in the workplace

\begin{tabular}{lll}
\hline \multicolumn{1}{c}{ Stage } & \multicolumn{1}{c}{ Action } & \multicolumn{1}{c}{ Comments } \\
\hline 1. Observation stage & Observations by trained company staff & $\begin{array}{l}\text { Simple, cheap and quick solutions to apparent and } \\
\text { recognized problems }\end{array}$ \\
\hline 2. Specialist stage & $\begin{array}{l}\text { Measurements by ergonomists or occu- } \\
\text { pational/industrial hygienists }\end{array}$ & $\begin{array}{l}\text { Accurate and reliable information about problems } \\
\text { as basis for decision on solutions }\end{array}$ \\
\hline 3. Expert stage & $\begin{array}{l}\text { Risk management program by experts in } \\
\text { occupational safety and health }\end{array}$ & $\begin{array}{l}\text { Overall assessment of risk factors and their man- } \\
\text { agement in a short and long term perspective }\end{array}$ \\
\hline
\end{tabular}

\section{Observations (stage 1)}

Many cold related problems are quite obvious and easy to recognize. People in the workplace have long experience of the local conditions and may come up with recommendations for solving specific problems. Engaging the workers in the process provides access to their knowledge and experience and allows for solutions that are based on the specific conditions in their workplace. Changes that are initiated by workers or with their engagement are more easily introduced and accepted.

Actions at the first stage are simple observations of the working conditions carried out in a systematic way. An observation checklist are helpful in this context and can be found in ISO 15743 ${ }^{14}$. A simplified version is found in Table 2. Typically representatives of the company are given a brief training about cold effects in humans and use of the checklist. An inspection is made of the workplaces and notes are taken in the checklist of problems that are observed. The observer should also consider the worst case, for example with changing weather conditions.

Each factor is observed and the risk is graded in three levels:

No problem: conditions are acceptable and there is no need for preventive actions

Slight problem: cold related problems are found that impairs conditions at the workplace. Effects, however, are judged as slight to moderate and corrective actions are not immediately required.
Table 2. Cold related risk factors to be observed and assessed during the inspection

\begin{tabular}{|c|c|c|c|}
\hline $\begin{array}{l}\text { Are these conditions causing } \\
\text { problems with cold? }\end{array}$ & No & $\begin{array}{l}\text { Yes, slight } \\
\text { problems }\end{array}$ & $\begin{array}{l}\text { Yes, severe } \\
\text { problems }\end{array}$ \\
\hline 1. Cold air & & & \\
\hline 2. Wind or high air velocities & & & \\
\hline 3. Contact with cold surfaces & & & \\
\hline $\begin{array}{l}\text { 4. Contact with cold fluids } \\
\text { and moisture }\end{array}$ & & & \\
\hline 5. Cold protective clothing & & & \\
\hline 6. Protection of hands and feet & & & \\
\hline $\begin{array}{l}\text { 7. Interference with other per- } \\
\text { sonal protective equipment }\end{array}$ & & & \\
\hline 8. Problems with snow and ice & & & \\
\hline 9. Other problems. Remarks: & & & \\
\hline
\end{tabular}

Indicate the magnitude of the problem with a mark in the column. Modified from Hassi et al. ${ }^{15)}$.

Severe problem: In order to ensure the safety and health of the workers and optimal productivity, this kind of problems should be immediately solved.

\section{Specialist investigation (stage 2)}

When problems are complex or costly to solve a specialist may be required for a more detailed and quantitative assessment. Some of the problems may require measurements for a more accurate evaluation. A series of international standards are available for this purpose. An overview of the standards is given in Fig. 1. An ergono-

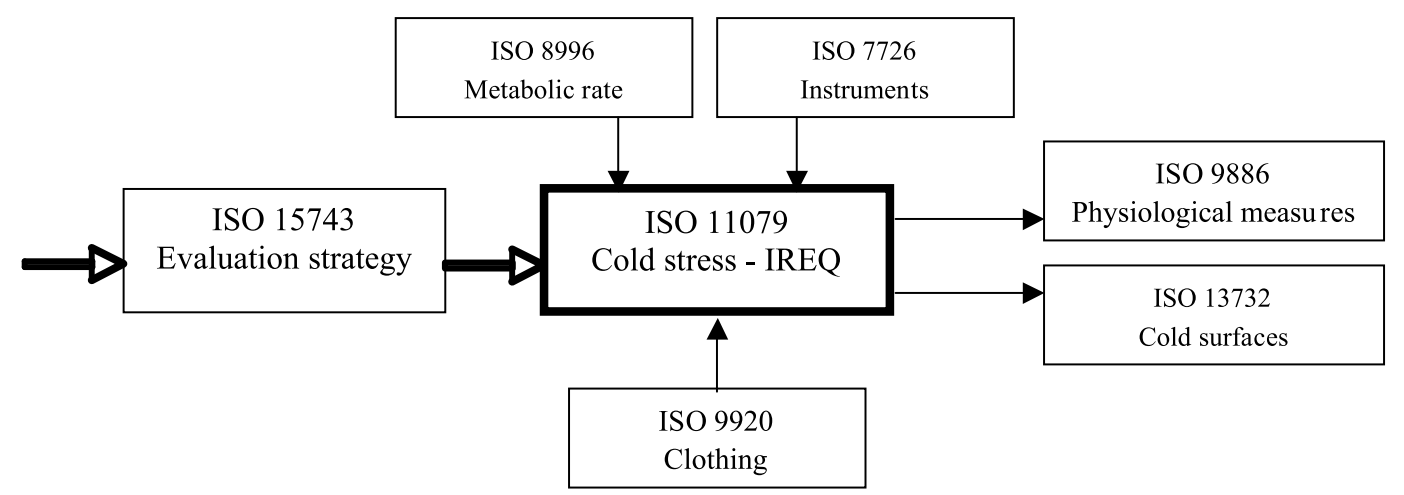

Fig. 1. Overview of international standards applicable to cold environments. 
Table 3. Examples of metabolic energy production associated with different types of work

\begin{tabular}{ccl}
\hline Class & $\begin{array}{c}\text { Average metabolic rate } \\
\mathrm{Wm}^{2}\end{array}$ & \multicolumn{1}{c}{ Examples } \\
\hline Resting & 65 & Resting \\
Low & 100 & $\begin{array}{l}\text { Light manual work; hand and arm work; driving vehicle in normal conditions; casual } \\
\text { walking (speed up to } 3.5 \mathrm{~km} / \mathrm{h} \text { ). }\end{array}$ \\
Moderate & 165 & $\begin{array}{l}\text { Sustained hand and arm work; arm and leg work; arm and trunk work; walking at } \\
3.5 \mathrm{~km} / \mathrm{h} \text { to } 5.5 \mathrm{~km} / \mathrm{h} .\end{array}$ \\
High & 230 & $\begin{array}{l}\text { Intense arm and trunk work; carrying heavy material; walking at } 5.5 \text { to } 7 \mathrm{~km} / \mathrm{h} . \\
\text { Very intense activity at fast pace; intense shoveling or digging; climbing stairs, ramp } \\
\text { or ladder; running or walking at a speed greater than } 7 \mathrm{~km} / \mathrm{h} .\end{array}$ \\
Very high & 290 & Sustained rescue work, wild land fire fighting. Endurance time less than $2 \mathrm{~h}$.
\end{tabular}

Modified from ISO $8996^{18)}$.

mist or and occupational or industrial hygienist should be familiar with these methods.

Principally, the effects of cold may be split up into whole body cooling and local cooling. Local cooling can be of different kinds. ISO 11079 deals with all these types of cold stress and gives advice on their evaluation.

- Whole body cooling

- Local cooling

$\circ$ extremity cooling

$\circ$ skin cooling by wind

$\circ$ skin cooling by contact

$\circ$ airway cooling

Whole body cooling

Adequate protective clothing is essential for the maintenance of heat balance in the cold. The method in ISO $11079^{1)}$ calculates the required clothing insulation (IREQ) for preserving heat balance at defined levels of physiological strain. The method is a further development of the classical approach by Belding ${ }^{16)}$ and Burton and Edholm ${ }^{17)}$. Four climatic factors need to be measured or estimated for the heat balance analysis. Air temperature and wind velocity are the two most important factors. Mean radiant temperature in many cases are similar to air temperature or higher due to solar radiation. Cold air (below $0^{\circ} \mathrm{C}$ ) is almost dry and humidity can arbitrarily be set to $85 \%$. Activity level (or metabolic heat production) is measured by the oxygen consumption of the person ${ }^{18}$. However, such measurements are cumbersome and costly. In practice, metabolic rate is estimated on the basis of tables describing typical activities ${ }^{1,18)}$. A few examples of activities and corresponding metabolic rates are given in Table 3.

The required clothing insulation for heat balance (IREQ) can now be calculated. A computer version of the IREQ-program is available. Figure 2 shows the program interface with boxes for input values and results.

Two values are given for IREQ representing two levels of physiological strain. The highest value should be

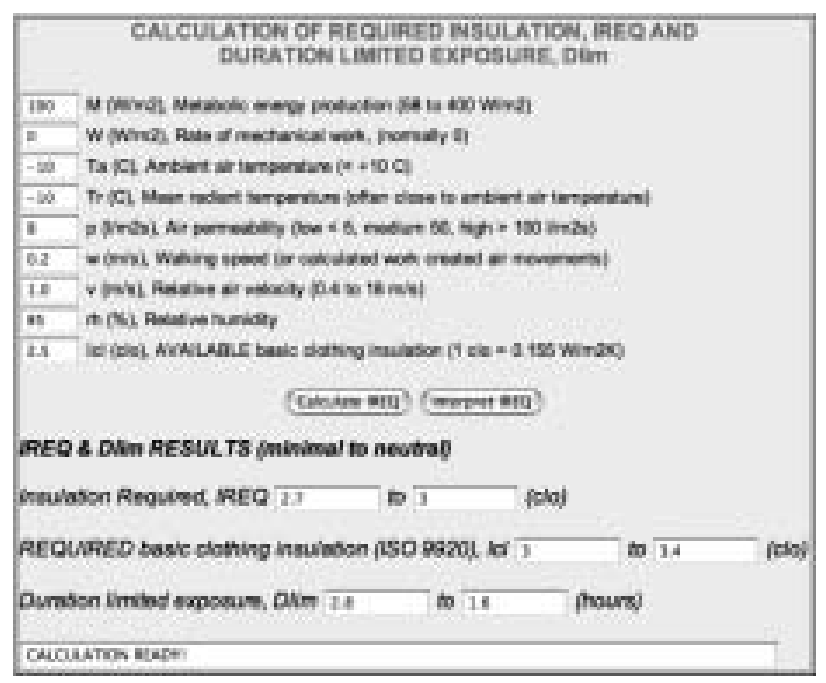

Fig. 2. Calculation program for IREQ and Duration limited exposure $\left(\mathbf{D}_{\text {lim }}\right)$.

Program can be found at wwwold.eat.lth.se/Research/Thermal/ TEL_ToolEn.htm.

regarded as a "comfort" value with little or no tissue cooling. The lower value corresponds to a drop in mean body temperature by $1^{\circ} \mathrm{C}$, which basically comes from skin cooling. IREQ is the insulation value actually required under prevailing wind and body movements. Evaluation of cold stress is made by comparing IREQ with the actual, available clothing insulation, corrected for the same wind and body movements. Figure 3 gives the IREQ value for "comfort" level for the activity classes in Table 3. It is readily seen that insulation requirements increase quickly at low temperatures when activity is low. At very high activity the insulation requirement is surprisingly small.

The thermal insulation value of the actual, worn clothing ensemble is measured according to ISO $17831^{19}$ ). In practice, the thermal insulation is estimated using tables in ISO 11079 or using any of the methods proposed in ISO-992020). Examples of insulation values for multi- 


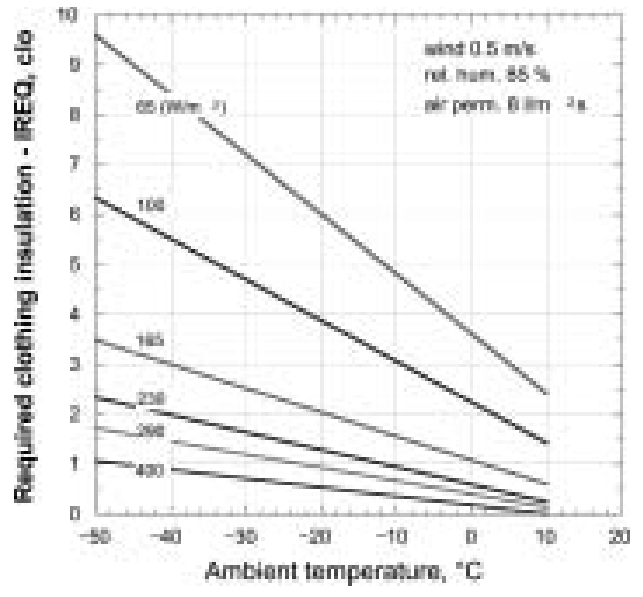

Fig. 3. Required clothing insulation (IREQ) for "comfort" at different activity levels and ambient air temperatures.

layer winter clothing are given in Table 4. The actual clothing insulation is a basic insulation value $\left(\mathrm{I}_{\mathrm{cl}}\right.$ see Fig. 2), meausered with a static thermal manikin in wind still conditions. This must be corrected for wind and body movements before comparison with IREQ, This is done automatically in the computer program.

If available insulation is close to the required insulation (IREQ), the exposure time may be infinite (as for values in Fig. 3). If IREQ is higher than the corrected, available insulation, protection is insufficient and a recommended exposure time $\mathrm{D}_{\text {lim }}$ is calculated (Fig. 4). For full protection a higher clothing insulation value is required. The value given in Fig. 4 is a basic insulation

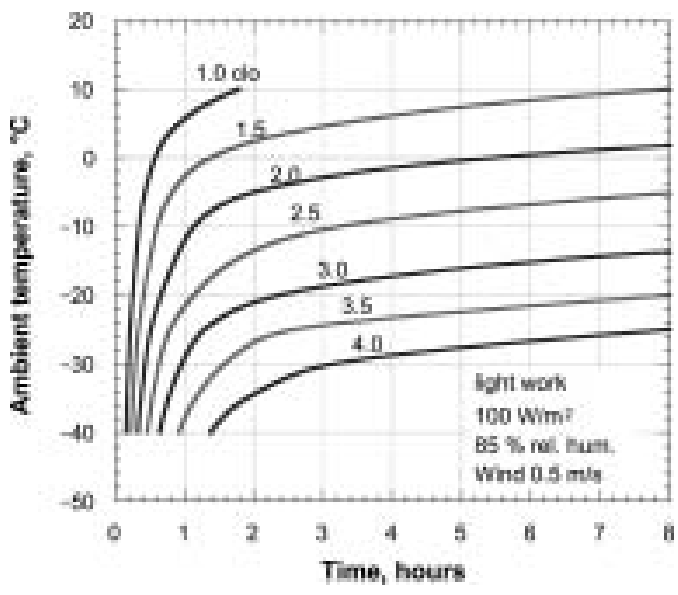

Fig. 4. Recommended exposure time for "comfort" cooling in clothing with different basic insulation values (cf Table 4).

With increasing insulation of clothing the exposure times at low temperatures becomes longer.

value ( $\mathrm{I}_{\mathrm{cl}}$ Fig. 2 and Table 4), as this kind of value is more easily found in tables ${ }^{20}$. An example for light work is given in Fig. 4. The criteria for cessation of exposure is a drop in mean skin temperature by about $3^{\circ} \mathrm{C}$ starting from "comfort" level (about $34^{\circ} \mathrm{C}$ ). At very low ambient temperatures only short exposure times are recommended also with highly insulative clothing. Longer exposures (hours) are achieved at progressively lower temperatures when insulation of clothing is increased.

If insulation value is higher than IREQ, clothing is too warm and must be adjusted to balance heat losses.

Table 4. Typical basic insulation values for cold protective clothing

\begin{tabular}{|c|c|c|c|}
\hline Ensemble & $\begin{array}{c}\text { Thermal } \\
\text { insulation, clo }\end{array}$ & $\begin{array}{l}\text { Thermal insulation, } \\
\mathrm{m}^{2 \circ} \mathrm{C} / \mathrm{W}\end{array}$ & $\begin{array}{l}\text { Calculated total water } \\
\text { vapor resistance, } \mathrm{Pam}^{2} / \mathrm{W}\end{array}$ \\
\hline $\begin{array}{l}2 \text { layers } \\
\text { Thin, long underwear, coverall }\end{array}$ & 1 & 0.155 & 34 \\
\hline $\begin{array}{l}3 \text { layers } \\
\text { Thin, long underwear, shirt and trousers, jacket }\end{array}$ & 1.5 & 0.23 & 45 \\
\hline $\begin{array}{l}3 \text { layers } \\
\text { Thin, long underwear, shirt and trousers, insulated jack- } \\
\text { et and trousers }\end{array}$ & 2 & 0.31 & 56 \\
\hline $\begin{array}{l}3 \text { layers } \\
\text { Thin, long underwear, fleece jacket and trousers, insu- } \\
\text { lated parca and overtrousers }\end{array}$ & 2.5 & 0.39 & 67 \\
\hline $\begin{array}{l}4 \text { layers } \\
\text { thick, long underwear, shirt and trousers, fleece jacket, } \\
\text { insulated parca and overtrousers }\end{array}$ & 3 & 0.47 & 78 \\
\hline $\begin{array}{l}4 \text { to } 5 \text { layers Arctic clothing } \\
\text { thick, long underwear, shirt, fleece jacket and trousers, } \\
\text { coverall, heavy insulated parca and overtrousers }\end{array}$ & 4 & 0.62 & $>100$ \\
\hline
\end{tabular}

All ensembles are combined with appropriate gloves, footwear and headgear. Modified from Holmér ${ }^{12}$. 


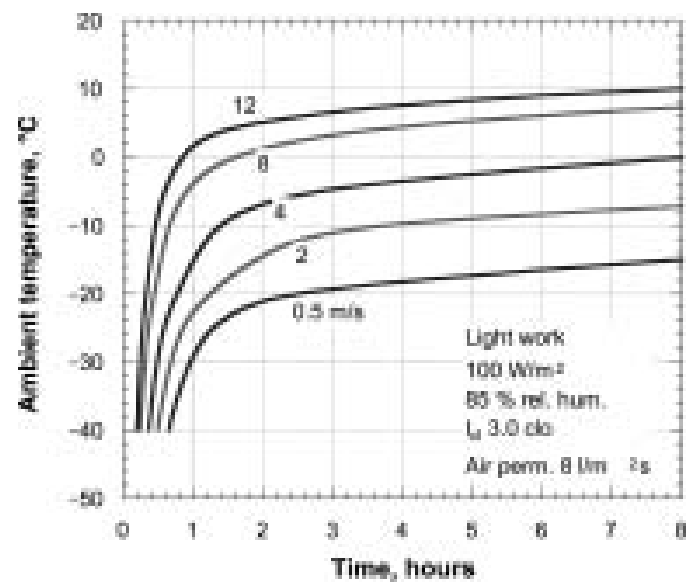

Fig. 5. Reduction in exposure time with increasing wind.

Basic clothing insulation is 3.0 clo and work is light.

Sweating must be avoided in cold work, as evaporative heat transfer is much limited by the high water vapor resistance values of cold protective clothing (Table 4). Sweating is otherwise condensed in layers causing discomfort and impaired insulation.

The outer layer fabric of cold protective clothing should be windproof (air permeability less than $10 \mathrm{l} / \mathrm{m}^{2} \mathrm{~s}$ (Fig. 5). The ensemble looses much of its insulative value in strong winds. An example is given in Fig. 5. An ensemble with a basic insulation of 3.0 clo and an air permeability of $8 \mathrm{l} / \mathrm{m}^{2} \mathrm{~s}$, accordingly provides protection for shorter time at any given activity and temperature.

\section{Local cooling}

Protection of hands and feet are strongly dependent of heat input by peripheral blood circulation and insulation by hand and foot gear ${ }^{21)}$. The insulation requirements at low activity and temperature is very large ${ }^{22)}$ and no glove can provide it. European standard EN 51123) describes two types of insulation to be measured: insulation against convective cooling (whole glove) and insulation against contact cooling (palm of glove). Tested gloves are assigned to any of four classes depending on test results - the higher class the better protection. Figure 6 describes the insulation requirements calculated according to Goldman ${ }^{24)}$.

ISO 11079 recommend frequent control of finger temperatures in the workplace and suggest that finger temperatures should be higher than $24^{\circ} \mathrm{C}$ for preservation of good hand function. Occasionally, finger temperatures down to $15^{\circ} \mathrm{C}$ may be acceptable, but dexterity, strength and coordination suffer and persons may complain about pain sensations.

One source of hand cooling is contact with cold surfaces. Touching or gripping cold materials may result in

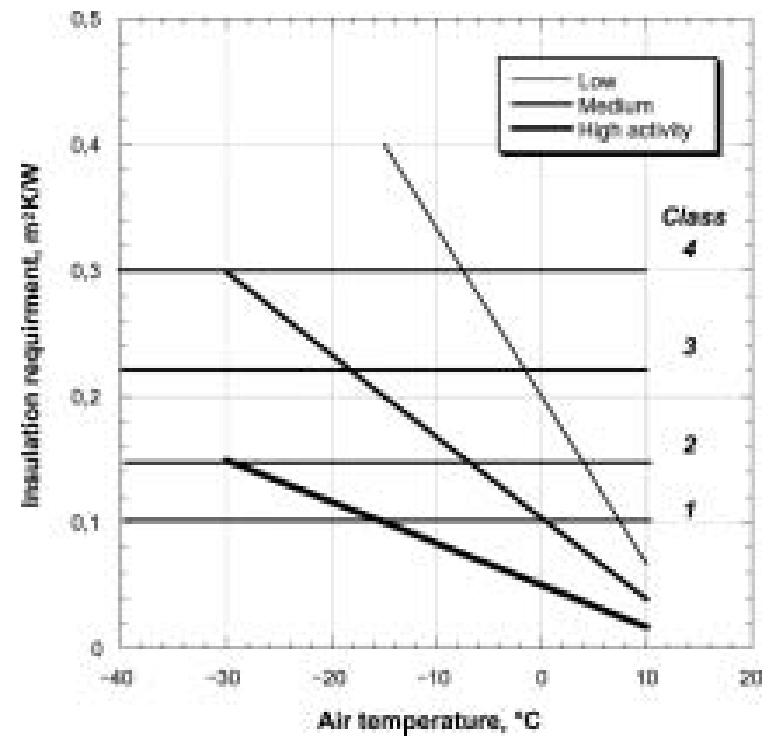

Fig. 6. Insulation requirements for gloves and mittens to maintain finger temperature above $+15^{\circ} \mathrm{C}$ at three different activity levels.

Horizontal lines indicate the different classes according to EN 511.

instantaneous, large drops in temperature of contacting tissue. ISO 13732 part $3^{2)}$ provides information about surface temperatures of different materials that can be touched. Three different criteria are given for the evaluation - pain sensation, numbness and frostbite. Numbness in the cold is associated with a deprivation of sensation. The function of fingers and hands is severely impaired and the risk of accidents and injury is imminent. Prediction of contact surface temperatures that cause numbness would be of great value. The temperature values apply to the naked skin (hand or finger) in contact with the surface at normal pressure. Gripping of a cold object can be done for longer times than a simple contact with for example a finger. This is due to the larger mass in contact but also by the behavioural adjustment of the grip pressure over time and surface.

Figure 7 gives an example of surface temperatures of different materials that upon contact in short time may develop numbness of skin. Figure 8 provides surface temperatures of different materials that would cause pain when gripped by the whole hand.

Strong cold winds contain significant power to cool warm skin causing pain, numbness and injury in short time. The wind chill index is well known and has been used for many years to identify potentially hazardous combinations of wind an low temperatures. New research has provided a new index, Wind Chill Temperature, that is based on a similar approach (Table 5). The Wind Chill Temperature is the air temperature of a uniform environment in which a person walks at a speed of $4.8 \mathrm{~km} / \mathrm{h}$ (rel- 


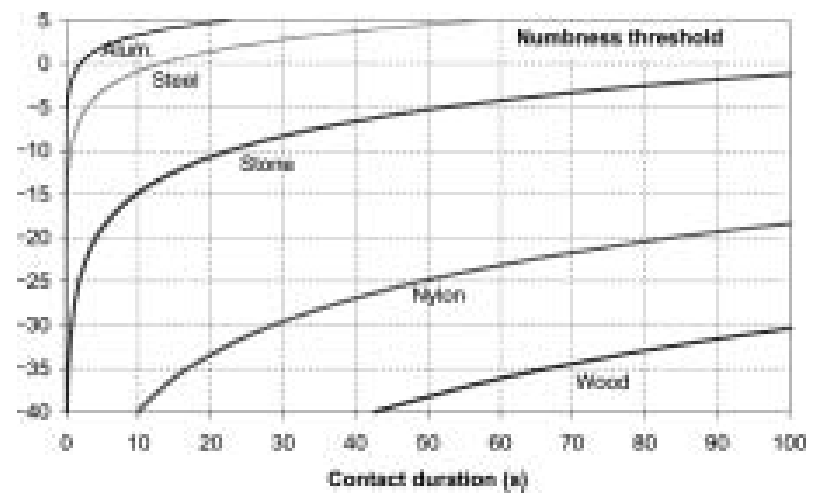

Fig. 7. Time for development of numbness when different materials are contacted by human skin. Modified from ISO 13732 Part 3.

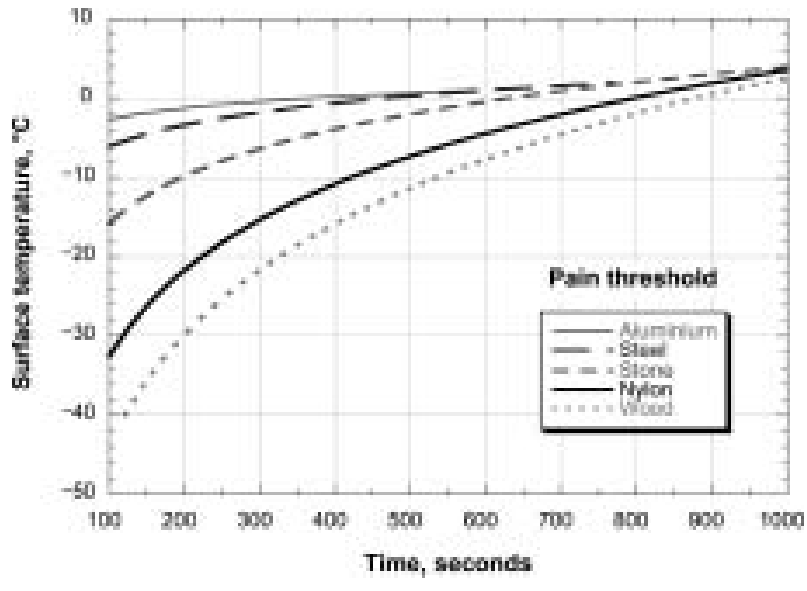

Fig. 8. Time for development of pain when different materials are gripped by the whole hand.

Modified from ${ }^{25}$.

Table 5. Wind Chill Temperatures for combinations of wind (at $10 \mathrm{~m}$ ) and air temperature.

\begin{tabular}{|cc|ccccccccc|}
\hline \multicolumn{2}{|c|}{ Wind at $10 \mathrm{~m}$} & \multicolumn{8}{|c|}{ Air temperature, ${ }^{\circ} \mathbf{C}$} \\
$\mathbf{k m} / \mathbf{h}$ & $\mathbf{m} / \mathbf{s}$ & $\mathbf{0}$ & $-\mathbf{5}$ & $-\mathbf{1 0}$ & $-\mathbf{1 5}$ & $-\mathbf{2 0}$ & $-\mathbf{2 5}$ & $-\mathbf{3 0}$ & $-\mathbf{3 5}$ & $-\mathbf{4 0}$ \\
\hline $\mathbf{5}$ & $\mathbf{1 . 5}$ & -2 & -7 & -13 & -19 & -24 & -30 & -36 & -41 & -47 \\
$\mathbf{1 0}$ & $\mathbf{3}$ & -3 & -9 & -15 & -21 & -27 & -33 & -39 & -45 & -51 \\
$\mathbf{2 0}$ & $\mathbf{6}$ & -5 & -12 & -18 & -24 & -31 & -37 & -43 & -49 & -56 \\
$\mathbf{3 0}$ & $\mathbf{9}$ & -7 & -13 & -20 & -26 & -33 & -39 & -46 & -52 & -59 \\
$\mathbf{4 0}$ & $\mathbf{1 2}$ & -7 & -14 & -21 & -27 & -34 & -41 & -48 & -54 & -61 \\
$\mathbf{5 0}$ & $\mathbf{1 5}$ & -8 & -15 & -22 & -29 & -35 & -42 & -49 & -56 & -63 \\
$\mathbf{6 0}$ & $\mathbf{1 8}$ & -9 & -16 & -23 & -30 & -37 & -43 & -50 & -57 & -64 \\
$\mathbf{7 0}$ & $\mathbf{2 1}$ & -9 & -16 & -23 & -30 & -37 & -44 & -51 & -59 & -66 \\
$\mathbf{8 0}$ & $\mathbf{2 4}$ & -10 & -17 & -24 & -31 & -38 & -45 & -52 & -60 & -67 \\
\hline
\end{tabular}

Light, medium and dark gray zones indicate increasing risks of developing frostbite. Modified from ISO 11079.

ative velocity is about $1.33 \mathrm{~m} / \mathrm{s}$ ). WCT is basically intended for weather forecasts and uses meteorological input data (e.g. wind speed at $10 \mathrm{~m}$ above ground). They are corrected by the calculation formula in order to refer to ground level. If wind speed is measured on the ground at a workplace the wind velocities in the two left columns of Table 5 must increased by 1.5 to give a correct WCTvalue. More information about WCT can be found at www.msc-smc.ec.gc.ca/education/windchill/index_e.cfm.

Inhalation of cold air may provoke respiratory distress symptoms, in particular in persons with asthma or other diseases. Also healthy persons may develop adverse effects on lung tissues when large volumes of very cold air is inhaled, for example during heavy work or athletic events at temperatures below -15 to $-20^{\circ} \mathrm{C}$. It is recommended to protect the airways by reducing work rate or exposure or by pre warming air by a breathing mask or similar.

\section{Expert Evaluation}

In the European Union mandatory Directives require the employer to identify occupational health risks in the workplace and environment, evaluate them and initiate preventive measures to control and eliminate risks. Many of the specific problems of cold stress can be assessed by available international standards, as previously described. An expert may be called to set up a complete program management of cold related risk factors. This must also include problems not covered by standards, for example work under changing work conditions, snowy and icy conditions, and use of special protective equipment.

A program needs to be set up for medical examination and control of workers employed in cold work. ISO $12894^{26)}$ and ISO $15743^{14)}$ deal with medical aspects of cold exposure. Exposure to cold may provoke or aggravate symptoms of persons with certain medical diagnosis such as hypertension, angina pectoris, Raynaud, and asthma. A medical check should be given persons employed 
at cold work places. A checklist for this purpose is provided in ISO 15743.

\section{Conclusions}

A step wise strategy for evaluation of cold related problems in the workplace can be applied. Simple observation techniques are used to identify and solve obvious and easy problems. A specialist is called when problems need to be quantified as a basis for selection of appropriate and cost effective preventive measures. A set of international standards are readily available for this purpose. Only for very complex problems and for the construction of a company risk management program the technical and medical experts need to be called.

\section{References}

1) ISO-11079 (2007) Ergonomics of the thermal environment. Determination and interpretation of cold stress when using required clothing insulation (IREQ) and local cooling effects.

2) ISO-13732/3 (2005) Ergonomics of the thermal environment - Assessment of human responses to contact with surfaces. Part 3 - Cold surfaces.

3) Holmér I, Granberg PO, Dahlström G (1997) Cold. In: Encyclopedia of Occupational Health, Stellman J (Ed.), 42.29-42.43, ILO, Geneva.

4) Enander A (1987) Effects of moderate cold on performance of psychomotor and cognitive tasks. Ergonomics 30, 1431-45.

5) Heus R, Daanen HAM, Havenith G (1995) Physiological criteria for functioning of hands in the cold. Appl Ergon 26, 5-13.

6) Piedrahita $\mathrm{H}$ (2008) Working in cold conditions indoors: effects on musculoskeletal symptoms and upper limb movements (Ph.D), Technical University, Luleå.

7) Gao C (2004) Slip and fall risks on ice and snow (Ph.D.). Technical University, Luleå.

8) Giesbrecht GG, Bristow GK (1997) Recent advances in hypothermia research. Ann N Y Acad Sci 15, 633-75.

9) Giesbrecht GG, Wilkerson JA (2006) Hypothermia, frotsbite and other cold injuries, The Mountaineeers Book, Seattle.

10) Lloyd EL (1986) Hypothermia and Cold Stress, Croom Helm, London.
11) Pozos R, Danzl D (2001) Human physiological responses to cold stress and hypothermia. In: Medical aspects of harsh environments, Pandolf K, Burr R (Eds.), 351-82, Borden Institute, Washington.

12) Holmér I (2008) Risk assessment for cold work. Journal of the Human-Environmental System 11, 1-5.

13) ISO-15265 (2000) Ergonomics of the thermal environment: risk assessment strategy for the prevention of stress or discomfort in thermal working conditions.

14) ISO-15743 (2008) Ergonomics of the thermal environment - Working practicies for cold environments.

15) Hassi J, Mäkinen T, Holmér I, Abeysekera J, Påsche A (2001) Risk assessment and management of cold related health hazards in arctic workplaces. Oulu Regional Institute of Occupational Hygiene: Final report to Barents Intereg IIA-program.

16) Belding HS (1949) Protection against dry cold. In: Physiology of heat regulation and the science of clothing, Newburgh L (Ed.), 351-67, Saunders, Philadelphia.

17) Burton AC, Edholm OG (1955) Man in a cold environment, Edward Arnold, New York.

18) ISO-8996 (2004) Ergonomics - Determination of metabolic heat production.

19) ISO-15831 (2003) Thermal manikin for measuring the resultant basic thermal insulation.

20) ISO-9920 (2008) Ergonomics of the thermal environment - Estimation of the thermal insulation and evaporative resistane of a clothing ensemble.

21) Kuklane K (2009) Protection of feet in cold exposure. Ind Health 47, 242-53.

22) van Dilla MA, Day R, Siple PA (1949) Special problems of the hands. In: Physiology of heat regulation, Newburgh R (Ed.), 374-88, Saunders, Philadelphia.

23) EN-511 (2005) Protective gloves against cold. Comité Européen de Normalisation, Brussells.

24) Goldman RF (1994) Local finger insulation and its effect on cooling rate. 6th International Conference on Environmental Ergonomics, Frim J, Ducharme MB, Tikuisis P (Eds.), 84-5, Montebello, Canada.

25) Holmér I, Geng Q, Havenith G, den Hartog E, Rintamäki H, Malchaire J, Piette A (2003) Temperature limit values for cold touchable surfaces: Arbete och Hälsa 2003: 7, Arbetslivsinstitutet, Stockholm.

26) ISO-12894 (2001) Ergonomics of the thermal environment - Medical supervision of individuals exposed to extreme hot or cold environments. 